\title{
Does lipid peroxidation and oxidative DNA damage differ in cryopreserved semen samples from young, adult and aged Nellore bulls?
}

\author{
Juliane Teramachi Trevizan ${ }^{\mathrm{a}, *}$, Janaina Torres Carreira ${ }^{\mathrm{a}}$, Isadora Resende Carvalho ${ }^{\mathrm{a}}$, \\ Bruna Helena Kipper ${ }^{\mathrm{a}}$, Walter Bertequine Nagata ${ }^{\mathrm{b}}$, Silvia Helena Venturoli Perri ${ }^{\mathrm{b}}$, \\ Maria Emilia Franco Oliveira ${ }^{c}$, Julia Cestari Pierucci ${ }^{c}$, Marion Burkhardt de Koivisto ${ }^{a}$ \\ ${ }^{a}$ Department of Medicine, Surgery and Animal Reproduction, School of Veterinary Medicine, São Paulo State University - UNESP, Araçatuba, São \\ Paulo, 16050-680, Brazil \\ b Department of Support, Production and Animal Health, School of Veterinary Medicine, São Paulo State University - UNESP, Araçatuba, São Paulo, \\ 16050-680, Brazil \\ ${ }^{\mathrm{c}}$ Department of Preventative Veterinary Medicine and Animal Reproduction, School of Agricultural and Veterinary Sciences, São Paulo State \\ University - UNESP, Jaboticabal, São Paulo, 14884-900, Brazil
}

\section{A R T I C L E I N F O}

\section{Keywords:}

Reactive oxygen species (ROS)

Sperm freezing

Cryopreservation

Aging

\begin{abstract}
A B S T R A C T
The aims of this study were to evaluate cryopreserved semen of Nellore bulls of different ages and verify whether sperm quality declines with advancing age and whether lipid peroxidation and DNA damage are involved in this process. For this purpose, 40 Nellore bulls were divided into three age groups: Young, aged $1.8-2$ years $(n=9)$; Adult, aged $3.5-7.0$ years $(n=19)$; and Seniors, aged 8.0-14.3 years $(n=12)$. Three ejaculates were collected from each bull, cryopreserved and evaluated for various parameters including membrane integrity, mitochondrial potential (FITC-PSA and JC1), lipid peroxidation (C-11BODIPY 581 / 591) and oxidative DNA damage (8OHdG) using flow cytometry. The thawed semen of senior bulls was characterized by a low percentage of motile sperm $(33.7 \pm 6.1 \%)$, higher damage to the plasma and acrosomal membrane $(37.5 \pm 9.8 \%)$, and low mitochondrial potential $(29.1 \pm 13.8 \%)$, as well as higher percentages of peroxidated cells $(53.6 \pm 12.2 \%)$ and DNA damage $(44.1 \pm 11.0 \%$; $\mathrm{P}<0.05)$. Lipid peroxidation was negatively correlated with motility $(\mathrm{r}=-0.35, \mathrm{P}<0.0002)$, average mitochondrial potential $(\mathrm{r}=-0.42 ; \mathrm{P}<0.0001)$ and showed a positive correlation with membrane injury and oxidative DNA damage $(r=039 ; \mathrm{P}=0.0003)$. Young bulls presented superior thawed sperm quality, possibly due to greater resistance to oxidative stress and, consequently, to cryopreservation. In conclusion, the sperm quality of bull semen declines with advancing age and is strongly associated with increased oxidative damage to both the plasma membrane and DNA.
\end{abstract}

\section{Introduction}

The effects of age on semen parameters have been intensely discussed in prepubertal to adult bulls, with the average studied age

\footnotetext{
* Corresponding author at: Rua Clóvis Pestana, 793, Prédio 87, Araçatuba, São Paulo, Brazil.

E-mail addresses: juliane.t.teramachi@hotmail.com (J.T. Trevizan), janababel@hotmail.com (J.T. Carreira), isadoraresende@hotmail.com (I.R. Carvalho), brunakipper@hotmail.com (B.H. Kipper), walter.bn@hotmail.com (W.B. Nagata), shvperri@fmva.unesp.br (S.H.V. Perri), m_emiliafraoli@yahoo.com.br (M.E. Franco Oliveira), juliapierucci@hotmail.com (J.C. Pierucci), koivisto@fmva.unesp.br (M.B.d. Koivisto).
} 
ranging from 1 to 7 years (Brito et al., 2004; Brito et al., 2002; Hallap et al., 2006, 2004). Despite many studies regarding the sexual maturity of young bulls, research evaluating the impact of advancing age on bull fertility, especially in senior animals, are scarce. The few existing studies indicate changes in spermatogenesis (Kumi-Diaka et al., 1981), lipid balance and production of antioxidants (Kelso et al., 1997). Much of the work done in the bovine seeks to relate sperm quality at different ages with other factors such as environmental, nutritional, breed differences and seasons of the year (Bhakat et al., 2011; Brito et al., 2002; Nichi et al., 2006).

Studies using mice as the experimental model indicate that increased DNA damage with aging is associated with increased susceptibility to oxidative stress (Zubkova et al., 2005; Zubkova and Robaire, 2006). This is because aging leads to the reduction of important antioxidant enzymes, such as superoxide dismutase (SOD) and glutathione peroxidase (GPx), which are responsible for protecting the sperm nucleus from free-radical attack, and some of the affected enzymes, such as peroxiredoxin, are fundamental for DNA stability (Weir and Robaire, 2006; Ozkosem et al., 2015). Recent studies also indicated that the germ cells of senior males show a reduced DNA repair mechanism and present inadequate response toward oxidative insults compared to young male germ cells (Paul et al., 2011; Selvaratnam et al., 2015).

Despite such evidence, most of the studies in bovines have aimed to evaluate the effects of ROS on sperm quality and function in cryopreservation protocols (Bilodeau et al., 2000; Gürler et al., 2015; Mostek et al., 2017). Few studies have evaluated the relationship between age and oxidative stress in bovine semen (Kelso et al., 1997), and no work has determined whether the age of the bull influences the oxidative damage in cryopreserved semen. This question is of fundamental importance in the search for prevention methods and alternative therapies that can optimize the sperm quality of high-genetic merit bulls with advanced age in seminal cryopreservation programs. Bos indicus cattle show late sexual maturation compared to Bos taurus (Nogueira, 2004) cattle and need more time to confirm genetic selection in progeny testing. In Brazil, commercialization of the semen of bulls with advanced age is a reality. Therefore, the objective of this study was to evaluate the quality of thawed semen from Nellore bulls of different age groups and test the hypothesis that the sperm quality of senior bulls declines because of increased oxidative damage.

\section{Materials and methods}

\subsection{Selection of animals}

A total of 40 healthy Nellore bulls from a sperm cryopreservation center located in the southeastern region of Brazil (21 $04^{\prime} 52^{\prime \prime} \mathrm{S}$ and $48^{\circ} 02^{\prime} 24^{\prime \prime}$ W) was used in this study and kept in a native pasture (Cynodon plectostachyus) with a balanced-energy diet. Three ejaculates were collected from each bull using the artificial vagina method within a twice-a-week collection schedule. Samples were cryopreserved (Tris-egg yolk, $7 \%$ glycerol in $250 \mu \mathrm{L}$ straws) according to the artificial insemination center standards and stored in liquid nitrogen until evaluation. Bulls were always handled by the same persons. Two technicians were involved in semen assessment, one of them for analysis pre-freezing and post-thawing and the other for cooling, packaging and freezing technique. The animals were divided into three groups according to age: (i) the Young group, aged from 1.8 to 2 years $(\mathrm{n}=9)$; the Adult group, aged between 3.5 and 7 years $(n=19)$; and the Senior group, aged from 8 to 14.3 years $(n=12)$. This classification was based on the study by KumiDiaka et al. (1981), who, through histological analysis of testicles, concluded that reproductive senility in bulls begins at 9 years of age. Bulls between 2 and 3 years are classified as young, and adults are considered mature between 5 and 6 years of age (Kelso et al., 1997).

\subsection{Microscopic evaluations and flow cytometry}

Microscopic evaluations were performed using an Olympus BX61 microscope (Olympus, Tokyo, Japan) equipped with a light field, phase contrast, differential interference contrast (DIC) and epifluorescence.

Flow cytometry analysis was performed with an Attune ${ }^{\circledR}$ instrument (Applied Biosystems by Life Technologies, Grand Island, NY, USA) equipped with $488 \mathrm{~nm}$ and $405 \mathrm{~nm}$ argon-ion lasers with the following emission filters: BL $1530 / 30 \mathrm{~nm}$ "bandpass" (BP), BL 2 575/24 nm BP, BL 3640 nm "long pass" (LP), VL 1 450/40 nm BP, VL 2 522/30 nm BP, and VL 3 603/48 nm BP.

\subsection{Motility, vigor and sperm morphology}

The straws were thawed at $35^{\circ} \mathrm{C}$ for $20 \mathrm{~s}$, and $5 \mu \mathrm{L}$ of semen was poured on a pre-warmed plate $\left(37^{\circ} \mathrm{C}\right)$, covered with a cover slip and visualized at 200X magnification. Sperm was evaluated for progressive motility (\%) and vigor (0 to 5), determined by visual estimation (CBRA, 2013). Vigor was analyzed using a scale from 0 (absence of any movement) to 5 (strong, vigorous forward movement) (CBRA, 2013).

To assess sperm abnormalities, 200 cells were counted using DIC (1000x). Sperm alterations were classified into major defects (i.e., primary acrosome defects, proximal droplets, abnormal loose heads, abnormal head contour, abnormal midpiece, nuclear vacuoles, double forms, and dag defects) and minor defects (abnormal head size, decapitated sperm head, coiled tails with cytoplasmic droplets, distal cytoplasmic droplets, abaxial midpiece) (Blom, 1973).

\subsection{Evaluation of plasma membrane and acrosome integrities}

For simultaneous evaluation of plasma membrane and acrosome integrities, one straw of each sample was thawed (35 $\left.{ }^{\circ} \mathrm{C} / 20 \mathrm{~s}\right)$, and the semen was diluted to $2 \times 10^{6}$ sperm in $200 \mu \mathrm{L}$ of PBS (phosphate buffered saline: NaCl $10 \mathrm{~g} / \mathrm{L} ; \mathrm{KCL} 0.25 \mathrm{~g} / \mathrm{L} ; \mathrm{NaH} 2 \mathrm{PO} 41.4 \mathrm{~g} /$ 
$\mathrm{L}$; free of CA2 + and $\mathrm{Mg} 2+)$, followed the addition of $3 \mu \mathrm{L}(0,2 \mathrm{mg} / \mathrm{mL}$ ) of propidium iodide (PI, Sigma, St. Louis, MO, USA.) and $50 \mu \mathrm{L}(100 \mu \mathrm{g} / \mathrm{mL})$ of fluorescein isothiocyanate conjugated with Pisum sativum (FITC-PSA, Sigma, St. Louis, MO, USA.). After incubation for eight minutes at $37{ }^{\circ} \mathrm{C}$ in a light-protected environment, all samples were measured with a flow cytometer, and 10.000 events were assessed using the argon-ion laser $(488 \mathrm{~nm})$, and a simultaneous reading was performed in BL 1 (530/30) and BL 3 (640 LP). For the positive control and compensation, samples were submitted to three cycles of "flash freezing" (Celeghini et al., 2010), aiming to promote membrane injury and consequent positive PI (red) and FITC-PSA (green) staining. The results were classified according to simultaneous evaluation of the membrane and acrosome integrities using the following categories: (i) intact plasma membrane and intact acrosome (IMIA), (ii) intact plasma membrane and damaged acrosome (IMDA), (iii) damaged plasma membrane and intact acrosome (DMIA), and (iv) damaged plasma membrane and damaged acrosome (DMDA). The damaged membrane (DM) and damaged acrosome (DA) parameters were analyzed by the (DMIA + DMDA) and (IMDA + DMDA) groupings, respectively.

\subsection{Evaluation of mitochondrial potential}

To evaluate the mitochondrial potential, the 5,5',6,6'tetrachloro-1,1',3,3'-tetraethylbenzimidazol-carbocyanine iodide fluorescence probe (JC-1, Sigma, St. Louis, MO, U.S.A) was used, which has the ability to distinguish mitochondria at high (orange fluorescence, $590 \mathrm{~nm}$ ) and low (green, $523-535 \mathrm{~nm}$ ) mitochondrial potential when excited by a $488 \mathrm{~nm}$ argon-ion laser (Gravance et al., 2001). For this purpose, $6 \mu \mathrm{L}$ of JC-1 $(153 \mu \mathrm{M})$ was added to $2 \times 10^{6}$ sperm in $200 \mu \mathrm{L}$ of PBS. The samples were incubated for $8 \mathrm{~min}$ at $37^{\circ} \mathrm{C}$ in a dark environment and read on the flow cytometer using argon-ion laser excitation ( $488 \mathrm{~nm}$ ), performing simultaneous readings on BL $1(530 / 30 \mathrm{~nm})$ and BL $2(575 / 24 \mathrm{~nm})$. For the control consisting of only low-mitochondrial potential cells, the samples were incubated with $10 \mu \mathrm{M}$ carbonyl cyanide-m-chlorophenylhydrazone (CCCP, Sigma, St. Louis, MO, USA) at $37^{\circ} \mathrm{C}$ for $30 \mathrm{~min}$ and stained with JC-1 according to the protocol described above. CCCP is a decoupling agent which frees protons by depolarizing the mitochondrial membrane (Brewis et al., 2000).

\subsection{Lipid peroxidation}

The C11-Bodipy 581/591 fluorescence probe (Molecular Probe, Eugene, OR) was used to evaluate lipid peroxidation. This probe is analogous to fatty acids and can be incorporated into the plasma membrane and fluoresce after lipid peroxidation. The probe fluoresces red when the membrane is intact and changes its emission when oxidation occurs, fluorescing green after attack by peroxyl and alkoxyl radicals (Drummen et al., 2002). For this experiment, the semen was thawed and adjusted to the concentration of $2 \times 10^{6}$ sperm in $200 \mu \mathrm{L}$ of PBS and centrifuged (500g).

The pellet was resuspended in $160 \mu \mathrm{l}$ of PBS, and $20 \mu \mathrm{l}$ of Bodipy581/591 (5 $\mu \mathrm{M})$ was added and incubated for $30 \mathrm{~min}$ at $37^{\circ} \mathrm{C}$. Eight minutes before the end of the incubation period, $1 \mu \mathrm{L}(2 \mathrm{mg} / \mathrm{ml})$ of propidium iodide was added to assess cell viability.

After addition of the fluorescent probes, the samples were washed and resuspended in $1 \mathrm{~mL}$ of PBS, as described by Brouwers and Gadella (2003). Then, 10.000 sperm excitations were conducted using the $488 \mathrm{~nm}$ argon-ion laser. The green/orange fluorescence reading (peroxidized cells) was performed using the BL1 filter (530/30 nm bandpass), and the fluorescence of the propidium iodide was detected using the BL3 filter ( $640 \mathrm{~nm}$ long pass). The positive control was performed by incubating a sperm sample in ferrous sulfate $(80 \mu \mathrm{M})$ for $60 \mathrm{~min}$ at $37^{\circ} \mathrm{C}$ (Aitken et al., 2007).

\subsection{Evaluation of oxidative damage to DNA}

The evaluation of DNA damage was performed using the OXIDNA ${ }^{\circledR}$ kit (Biotrin International LTDA, Dublin, Ireland), which quantifies 8-hydroxy 2'-deoxyguanosine ( $8 \mathrm{OHdG})$, which is the final product of the oxidation of guanine by the hydroxyl radical (OH •) (De Iuliis et al., 2009). For measurement, the semen of a thawed sample from each straw was washed with PBS, resuspended in $100 \mu \mathrm{L}$ of dithiothreitol $(2 \mathrm{mM})$ and incubated at $37^{\circ} \mathrm{C}$ for $45 \mathrm{~min}$. Subsequently, the semen was washed with $100 \mu \mathrm{L}$ of $4 \%$ paraformaldehyde in $100 \mu \mathrm{L}$ of PBS and maintained at $4{ }^{\circ} \mathrm{C}$ for $15 \mathrm{~min}$. After fixation and rinsing with PBS, the cells were incubated in $100 \mu \mathrm{L}$ of Triton X 100 at room temperature for $15 \mathrm{~min}$. Next, they were washed with the "Wash solution" contained in the OXYDNA kit and diluted to a ratio of 1:25 in distilled water. The samples were incubated for 60 min at room temperature in a solution containing one part of the FITC-conjugated anti-8-OHdG antibody solution diluted in nine parts of the wash solution. The stained samples were rinsed and resuspended in $1 \mathrm{~mL}$ of PBS. After the staining protocol, reading was performed using flow cytometry, with 10.000 sperm excitation events were conducted using the $488 \mathrm{~nm}$ argon-ion laser and the BL1 filter (530/30 nm bandpass). The positive control was performed by incubating a sperm sample in DDT for $45 \mathrm{~min}$ and conditioning in hydrogen peroxide ( $2 \mathrm{mM}$ ) and ferrous sulfate (1 mM) for $60 \mathrm{~min}$ (De Iuliis et al., 2009).

\subsection{Statistical analysis}

Statistical analysis was performed using SAS software, previously "Statistical Analysis System" (release 9.2 SAS Institute Inc., Cary, NC, USA, 2008). Data percentages were converted into arcosene to obtain a normal distribution. The results were analyzed using oneway ANOVA. The Pearson correlation coefficient was applied to evaluate the effect of lipid peroxidation on the semen parameters (motility, mitochondrial potential, IMIA, IMDA, DMIA, DMDA, DM, DA, and DNA damage). Means were compared using the Tukey test and considered significant when $\mathrm{P}<0.05$. 
Table 1

Mean and standard deviation of motility, vigor and major, minor and total sperm abnormalities of the post-thawing semen of young ( $\mathrm{n}=9$ ), adult $(\mathrm{n}=19)$ and senior $(\mathrm{n}=12)$ Nellore bulls.

\begin{tabular}{|c|c|c|c|}
\hline Parameters & $\begin{array}{l}\text { Young } \\
1.9 \pm 0.09 \text { years }[1.8-2.0]\end{array}$ & $\begin{array}{l}\text { Adult } \\
4.7 \pm 0.9 \text { years }[3.5-7.0]\end{array}$ & $\begin{array}{l}\text { Senior } \\
10.1 \pm 2.0 \text { years }[8.0-14.3]\end{array}$ \\
\hline Motility (\%) & $38.9 \pm 10.9^{\mathrm{a}}$ & $38.2 \pm 8.8^{\mathrm{a}}$ & $33.7 \pm 6.1^{\mathrm{b}}$ \\
\hline Vigor (1-5) & $3.7 \pm 0.7$ & $3.6 \pm 0.6$ & $3.5 \pm 0.4$ \\
\hline Major sperm abnormalities (\%) & $13.7 \pm 5.0^{\mathrm{a}}$ & $9.3 \pm 5.7^{b}$ & $9.2 \pm 4.7^{\mathrm{b}}$ \\
\hline Minor sperm abnormalities (\%) & $5.1 \pm 3.3^{\mathrm{a}}$ & $6.3 \pm 3.9^{\mathrm{a}}$ & $6.3 \pm 5.0^{\mathrm{a}}$ \\
\hline Total sperm abnormalities (\%) & $18.8 \pm 7.0^{\mathrm{a}}$ & $14.5 \pm 7.8^{\mathrm{b}}$ & $15.1 \pm 6.4^{\mathrm{ab}}$ \\
\hline
\end{tabular}

${ }^{\mathrm{a}, \mathrm{b}}$ Means within a row with different superscripts are different (Tukey test; $\mathrm{P}<0.05$ ).

\section{Results}

The semen parameters of young, adult and senior bulls are summarized in Table 1. Sperm motility of young and adult animals was higher $(\mathrm{P}<0.05)$ compared to that of the seniors, but no difference was observed in relation to vigor. Regarding spermatozoa defects, differences were observed in both major and total abnormalities. The post-thawing semen of young bulls was characterized by a higher percentage of major defects compared to that of adults and seniors $(\mathrm{P}<0.05)$, whereas a higher percentage of total abnormalities was observed for young bulls in comparison to adults.

Young bulls had a higher percentage of sperm with IMIA compared adults and seniors $(\mathrm{P}<0.05$; Table 2). The percentage of sperm with IMDA was lower in young and adult bulls and higher in senior bulls $(\mathrm{P}<0.05)$. No significant difference was observed in DMDA between the groups. However, the sperm of senior bulls presented a high percentage of AD and DM when DMDA was added with IMDA and DMIA, respectively $(\mathrm{P}<0.05)$.

Mitochondrial activity was also influenced by the "age effect" $(\mathrm{P}<0.05)$, with young bulls showing higher percentages of sperm with high mitochondrial potential after thawing compared to that of adult and senior bulls. However, the percentage of cells with low mitochondrial potentials after thawing was higher in adult and senior bulls $(\mathrm{P}<0.05$; Table 3$)$.

Lipid peroxidation in the plasma membrane was higher $(\mathrm{P}<0.05)$ in the sperm of senior bulls compared to the young bulls, while adult bulls presented a percentage similar to both groups. The percentage of sperm with oxidative DNA damage was higher in sperm of senior bulls, followed by adults and lastly by young bulls $(\mathrm{P}<0.05$, Table 4$)$.

The correlations between lipid peroxidation in the plasma membrane and sperm parameters, such as motility, mitochondrial potential, membrane integrity and DNA damage are presented in Table 5. Lipid peroxidation was negatively correlated with motility $(\mathrm{r}=-0.35 ; \mathrm{P}<0.00002)$ and average mitochondrial potential $(\mathrm{r}=-0.42 ; \mathrm{P}<0.0001)$ and positively correlated with DMIA $(\mathrm{r}=0.34 ; \mathrm{P}=0.00002)$, DMDA $(\mathrm{r}=0.19 ; \mathrm{P}=0.0496), \mathrm{DM}(\mathrm{r}=0.32 ; \mathrm{P}=0.0006)$ and oxidative DNA damage $(\mathrm{r}=0.39$; $\mathrm{P}=0.0003)$.

\section{Discussion}

This study clearly showed that susceptibility to oxidative stress in semen after thawing is influenced by age. Senior bulls were characterized by sperm cells with low motility, reduced mitochondrial potential, high plasma and acrosomal membrane damage, and a higher percentage of spermatozoa with oxidative lesions on the plasma membrane and DNA when compared to young bulls and adults.

The research also showed the relationship between lipid peroxidation and seminal parameters, which were negatively characterized with motility and average mitochondrial potential, and positively with damage of plasma membrane and DNA.

\section{Table 2}

Mean and standard deviation of the percentage of sperm as to intact plasma membrane and acrosome (IMIA), intact plasma membrane and damaged acrosome (IMDA), damaged plasma membrane and intact acrosome (DMIA), damaged plasma membrane and acrosome (DMDA), damaged acrosome (DA) and damaged plasma membrane (DM), post-thawing and staining with FITC-PSA and PI fluorescent probes of the young $(\mathrm{n}=9)$, adult $(\mathrm{n}=19)$ and senior $(\mathrm{n}=12)$ groups evaluated by flow cytometry.

\begin{tabular}{|c|c|c|c|}
\hline Parameters & $\begin{array}{l}\text { Young } \\
1.9 \pm 0.09 \text { years }[1.8-2.0]\end{array}$ & $\begin{array}{l}\text { Adult } \\
4.7 \pm 0.9 \text { years }[3.5-7.0]\end{array}$ & $\begin{array}{l}\text { Senior } \\
10.1 \pm 2.0 \text { years }[8.0-14.3]\end{array}$ \\
\hline IMIA (\%) & $54.7 \pm 9.5^{\mathrm{a}}$ & $46.7 \pm 10.1^{b}$ & $37.5 \pm 9.8^{c}$ \\
\hline IMDA (\%) & $10.6 \pm 8.4^{\mathrm{b}}$ & $14.5 \pm 10.4^{b}$ & $20.7 \pm 13.4^{\mathrm{a}}$ \\
\hline DMIA (\%) & $12.8 \pm 4.9^{b}$ & $15.1 \pm 5.4^{\mathrm{ab}}$ & $16.6 \pm 6.4^{a}$ \\
\hline DMDA (\%) & $21.9 \pm 9.4$ & $23.7 \pm 7.0$ & $25.1 \pm 8.5$ \\
\hline $\mathrm{DA}^{*}(\%)$ & $32.5 \pm 8.7^{\mathrm{c}}$ & $38.2 \pm 11.5^{\mathrm{b}}$ & $45.8 \pm 13.7^{\mathrm{a}}$ \\
\hline $\mathrm{DM}^{* *}(\%)$ & $34.7 \pm 12.2^{\mathrm{b}}$ & $38.8 \pm 9.7^{\mathrm{ab}}$ & $41.7 \pm 10.6^{\mathrm{a}}$ \\
\hline
\end{tabular}

\footnotetext{
${ }^{\mathrm{a}, \mathrm{b}}$ Means within a row with different superscripts are different (Tukey test; $\mathrm{P}<0.05$ ).

$*$ DA $=$ DMDA + IMDA.

$* * \mathrm{DM}=$ DMDA + DMIA.
} 


\section{Table 3}

Mean and standard deviation of the percentage of sperm with high mitochondrial potential, average mitochondrial potential and low mitochondrial potential, post-thawing and stained by JC1 and FITC-PSA fluorescent probes of the young $(n=9)$, adult $(n=19)$ and senior ( $n=12)$ groups, evaluated by flow cytometry.

\begin{tabular}{lll}
\hline Parameters & Young & Adult \\
& $1.9 \pm 0.09$ years $[1.8-2.0]$ & $\begin{array}{l}\text { Senior } \\
10.1 \pm 2.0 \text { years }[3.5-7.0]\end{array}$ \\
\hline High mitochondrial potential (\%) & $81.7 \pm 9.4^{\mathrm{a}}$ & $67.8 \pm 10.4^{\mathrm{b}}$ \\
Average mitochondrial potential (\%) & $13.4 \pm 6.6^{\mathrm{a}}$ & $7.8 \pm 4.6^{\mathrm{b}}$ \\
Low mitochondrial potential (\%) & $4.9 \pm 4.2^{\mathrm{b}}$ & $24.4 \pm 12.6^{\mathrm{a}}$ \\
\hline
\end{tabular}

${ }^{\mathrm{a}, \mathrm{b}}$ Means within a row with different superscripts are different (Tukey test; $\mathrm{P}<0.05$ ).

Table 4

Mean and standard deviation of the percentage of cells showing peroxidative damage in the plasma membrane (Bodipy ${ }^{581 / 591}$ ) and DNA (OxDNA kit) in the post-thawing semen of the young $(n=9)$, adult $(n=19)$ and senior $(n=12)$ groups, evaluated by flow cytometry.

\begin{tabular}{|c|c|c|c|}
\hline Parameters & $\begin{array}{l}\text { Young } \\
1.9 \pm 0.09 \text { years }[1.8-2.0]\end{array}$ & $\begin{array}{l}\text { Adult } \\
4.7 \pm 0.9 \text { years }[3.5-7.0]\end{array}$ & $\begin{array}{l}\text { Senior } \\
10.1 \pm 2.0 \text { years }[8.0-14.3]\end{array}$ \\
\hline Bodipy (\%) & $43.3 \pm 9.1^{\mathrm{a}}$ & $49.0 \pm 9.5^{\mathrm{ab}}$ & $53.6 \pm 12.2^{\mathrm{b}}$ \\
\hline Oxydna (\%) & $25.7 \pm 6.2^{\mathrm{c}}$ & $34.9 \pm 9.2^{\mathrm{b}}$ & $44.1 \pm 11.0^{\mathrm{a}}$ \\
\hline
\end{tabular}

${ }^{\mathrm{a}, \mathrm{b}}$ Means within a row with different superscripts are different (Tukey test; $\mathrm{P}<0.05$ ).

Table 5

Correlation coefficient and P-value between lipid peroxidation and motility, plasma membrane and acrosome integrity and DNA oxidative damage in post-thawed semen of young $(n=9)$, adults $(n=19)$, senior $(n=12)$ bulls.

\begin{tabular}{llc}
\hline \multirow{2}{*}{ Parameters } & \multicolumn{2}{l}{ Lipid Peroxidation $\left(\right.$ Bodipy $\left.^{581 / 591}\right)$} \\
\cline { 2 - 3 } & Correlation & P-value \\
\hline Motility & -0.35 & $<0.0002$ \\
High mitochondrial potential & 0.01 & 0.8845 \\
Average mitochondrial potential & -0.42 & $<0.0001$ \\
Low mitochondrial potential & 0.17 & 0.0665 \\
IMIA & -0.15 & 0.1047 \\
IMDA & 0.15 & 0.1235 \\
DMIA & 0.34 & 0.0002 \\
DMDA & 0.19 & 0.0492 \\
DM & 0.32 & 0.0006 \\
DA & 0.01 & 0.8845 \\
DNA oxidative damage & 0.39 & 0.0003 \\
\hline
\end{tabular}

"IMIA: intact plasma membrane and acrosome, IMDA: intact plasma membrane and damaged acrosome, DMIA: damaged plasma membrane and intact acrosome, DMDA: damaged both plasma membrane and acrosome, DM: damaged membrane, DA: damaged acrosome.

The decrease in sperm motility with aging has also been described in older Bos taurus bulls ( $>9$ years of age) and was associated with a significant reduction of polyunsaturated (PUFAs) and unsaturated fatty acids (arachidonic and docosahexaenoic acid, respectively) and the antioxidant enzymes SOD and GPx (Kelso et al., 1997). Recent studies have reported that the sperm lipid composition and the antioxidant capacity of semen prior to cryopreservation may be crucial factors for the viability of thawed semen, since a higher concentration of PUFAs confers greater fluidity and flexibility in the sperm membrane to handle osmotic stress, as well as physical and oxidative effects of cryopreservation (Am-in et al., 2011; Macías García et al., 2011; Tapia et al., 2012; ArgovArgaman et al., 2013). Age interference with the lipid metabolism of spermatozoa in antioxidant activity and, consequently, sperm functionality and the impact of this alteration on frozen semen has not been described in Bos indicus bulls but may be a factor for consideration in future studies involving age.

Reduction of motility, viability, and mitochondrial potential and increased membrane and DNA peroxidative damage are expected characteristics in cryopreserved semen (Gürler et al., 2016; Castro et al., 2015). This is because thawed semen loses significant amounts of SOD and GPx and has increased levels of superoxide anion and hydrogen peroxide (Bilodeau et al., 2000; Chatterjee and Gagnon, 2001). The freezing and thawing process can lead to disturbances in the mitochondria, characterized by increased pore permeability of the mitochondria, which results in loss of sperm motility, mitochondrial potential and apoptosis induction (Bilodeau et al., 2000; Peña et al., 2009).

The effects of lipid peroxidation on semen parameters were demonstrated by negative correlation with sperm motility, average mitochondrial potential and positive correlation with membrane injury and oxidative DNA damage. This relationship between lipid peroxidation and motility in bovine semen has been reported in other studies (Bilodeau et al., 2000; Weir and Robaire, 2006). 
Cytotoxic aldehydes and lipid peroxides generated during peroxidation reactions impair important motility control centers such as ion channels, ATP-dependent pumps and mitochondrial proteins (Lundbeek and Andersen, 1994), inducing the opening of mitochondrial pores and reducing mitochondrial potential (Peña et al., 2009). Increased mitochondrial permeability favors the release of apoptotic mediators such as hydrogen peroxide, which eventually induces oxidative DNA damage and cell death (Aitken et al., 2016).

Interestingly, lipid peroxidation showed a negative correlation with spermatozoa with average mitochondrial potential, but not with those of high and low mitochondrial potential. Negative correlation between lipid peroxidation (C11-Bodipy581 / 591) and high mitochondrial potential has been observed in the cryopreserved semen of stallions (Ortega Ferrusola et al., 2009). In cattle, this relationship has not yet been tested (Brouwers and Gadella, 2003; Gürler et al., 2015), thus it is possible that lipid peroxidation in thawed bovine semen is associated with a population of spermatozoa presenting more heterogeneous mitochondrial potential.

In light of 1) differences in seminal parameters between age groups, especially the increase of oxidative damage in the ejaculate of elderly bulls; 2) high percentage of cells presenting high mitochondrial potential, motility and viability in the ejaculate of young bulls; and 3) low mitochondrial potential in adult and elderly bulls; it is tempting to suggest that mitochondrial dysfunction is associated with aging, and that cryopreservation may exacerbate the problem.

In a recent study, Darr et al. (2017) evaluated mitochondrial oxygen consumption in cryopreserved semen of stallions and showed that increased age (12 years of age) correlated with an increase in oxygen consumption, ROS production and, consequently, reduced motility compared to young animals.

Studies indicate that susceptibility to oxidative stress with aging is linked to three factors: low antioxidant activity in the ejaculate, inadequate germ cell response to ROS, and deficiency of the DNA repair mechanism in spermatogenesis (Weir and Robaire, 2006; Paul et al., 2011; Selvaratnam et al., 2015). The reduction of antioxidant activity in sperm of senior mice resulted in high production of ROS, which was associated with increased lipid peroxidation (Weir and Robaire, 2006). It is worth mentioning that in response to superoxide anion generation, this molecule is converted to hydrogen peroxide by the superoxide dismutase enzyme, and in the presence of catalase, the hydrogen peroxide turns into water (Aitken et al., 2016). When germ cells of young mice were exposed to ROS, they responded by reducing the expression of superoxide dismutase to prevent accumulation of hydrogen peroxide. However, the senior group showed an opposite response-that is, the expression of superoxide dismutase was elevated, and catalase was reduced, inducing an imbalance of the redox axis that culminated with accumulation of hydrogen peroxide and, consequently, in the loss of viability and an increase of DNA damage in spermatocytes (Selvaratnam et al., 2015). Hydrogen peroxide is an important mediator of apoptosis and DNA fragmentation in human sperm (De Iuliis et al., 2009). Although it has not been the focus of our study to directly assess the ROS level in semen, we believe that hydrogen peroxide participates in DNA damage, since studies have shown the role of this radical in bovine sperm DNA fragmentation (Gürler et al., 2015) and, therefore, its deleterious effect on embryonic development (Castro et al., 2016).

To our knowledge, this is the first study reporting the consequences of aging and oxidative stress on the sperm quality of cryopreserved bovine semen. The reduction of sperm motility, mitochondrial potential, and membrane and acrosome integrity and the increase of membrane and DNA oxidative damage in thawed sperm of senior bulls indicate that age should be an important factor considered in the choice of diluents, cryoprotectants, and antioxidants to optimize results. For example, cryopreservation of senior bull sperm may be enhanced by the use of mitochondria-targeted antioxidants or mitochondrial metabolic modulators, such as MitoQ, which showed good results in reducing lipid peroxidation and increasing the viability of thawed semen of Yellowfish (Fang et al., 2014). Dietary supplementation may also be an alternative, since the greater fragility of senior bull semen in cryopreservation and its susceptibility to oxidative stress may bring a new perspective on the use of PUFAs and/or inclusion of antioxidants in the diet of animals. Several studies have described that incorporation of PUFAs in the diet improves sperm quality in both fresh and frozen semen (Gürler et al., 2015; Selvaratnam et al., 2015; Khoshvaght et al., 2016; Van Tran et al., 2017) and that animals with lowquality semen may be major beneficiaries of this type of supplementation (Byrne et al., 2017).

In summary, age negatively influences sperm quality in Nellore bulls due to higher susceptibility to oxidative damage. Sperm of young and adult bulls presented better post-thaw sperm quality, possibly due to higher resistance to oxidative stress and, consequently, to cryopreservation.

\section{Ethics approval and consent to participate}

Not applicable, semen collected and commercialized by insemination centre.

\section{Conflict of interest}

None.

\section{Funding}

We thank the São Paulo Research Foundation (FAPESP) for the financial support (2011/22741-1; 2011/16614-2).

\section{Acknowledgements}

The authors thank Lúcia Helena Rodrigues for providing the samples, Life Technologies for their support with supplies, Prof. 
Silvia Helena V. Perri and Walter B. Nagata for contributing to statistical analysis. Juliane T. Trevizan carried out the semen evaluation and wrote the manuscript; Janaina T. Carreira; Isadora R. Carvalho, Bruna H. Kipper participated in semen evaluation; Maria E. F. Oliveira and Júlia C. Pierucci helped revising the manuscript, and Marion B. Koivisto was the organizer and the principal investigator. All the authors have read and approved the final manuscript.

\section{References}

Am-in, N., Kirkwood, R.N., Techakumphu, M., Tantasuparuk, W., 2011. Lipid profiles of sperm and seminal plasma from boars having normal or low sperm motility. Theriogenology 75, 897-903.

Aitken, R.J., Wingate, K.J., De Iuliis, N.G., McLaughin, A.E., 2007. Analysis of lipid peroxidation in human spermatozoa using Bodipy C11. Mol. Hum. Reprod. 13, $203-211$.

Aitken, R.J., Gibb, Z., Baker, A.M., Drevet, J., Gharagozloo, P., 2016. Causes and consequences of oxidative stress in spermatozoa. Reprod. Fertil. Dev. 28, 1-10.

Argov-argaman, N., Mahgrefthe, K., Zeron, Y., Roth, Z., 2013. Variation in lipid profiles within semen compartments d the bovine model of aging. Theriogenology 80, $712-721$.

Bhakat, M., Mohanty, T.K., Raina, V.S., Gupta, A.K., Khan, H.M., Mahapatra, R.K., Sarkar, M., 2011. Effect of age and season on semen quality parameters in Sahiwal bulls. Trop. Anim. Health Prod. 43, 1161-1168.

Bilodeau, J.F., Chatterjee, S., Sirard, M.A., Gagnon, C., 2000. Levels of antioxidant defenses are decreased in bovine sperm after a cycle of freezing. Mol. Reprod. Dev. 288, 282-288.

Blom, E., 1973. The ultrastructure of some characteristic sperm defects and a proposal for a new classification of the bull spermiogram (author's transl). Nord. Vet. Med. 25, 383-391.

Brewis, I.A., Morton, I.E., Mohammad, S.N., Browes, C.E., Moore, H.D., 2000. Measurement of intracellular calcium concentration and plasma membrane potential in human sperm using flow cytometry. J. Androl. 21, 238-249.

Brito, L.F.C., Silva, A.E.D.F., Unanian, M.M., Dode, M.A.N., Barbosa, R.T., Kastelic, J.P., 2004. Sexual development in early- and late-maturing Bos indicus and Bos indicus x Bos taurus crossbred bulls in Brazil. Theriogenology 62, 1198-1217.

Brito, L.F., Silva, A.E., Rodrigues, L.H., Vieira, F.V., Deragon, L.A., Kastelic, J.P., 2002. Effects of age and genetic group on characteristic of scrotum, testis and testicular vascular cone and on sperm production and semen quality of AI bulls in Brazil. Theriogenology 58, $1175-1186$.

Brouwers, J.F.H.M., Gadella, B.M., 2003. In situ detection and localization of lipid peroxidation in individual bovine sperm cells. Free Radic. Biol. Med. 35, $1382-1391$.

Byrne, C.J., Fair, S., English, A.M., Holden, S.A., Dick, J.R., Lonergan, P., Kenny, D.A., 2017. Dietary polyunsaturated fatty acid supplementation of young postpubertal dairy bulls alters the fatty acid composition of seminal plasma and sperm but has no effect on semen volume or sperm quality. Theriogenology 90 , 289-300.

Castro, L.S., De Assis, P.M., Siqueira, A.F.P., Hamilton, T.R.S., Mendes, C.M., Losano, J.D.A., Nichi, M., Visintin, J.A., Assumpção, M.E.O.A., 2015. Sperm oxidative stress is detrimental to embryo development: a dose-dependent study model and new and more sensitive oxidative status evaluation. Oxid. Med. Cell. Longev. 2016, 1-12.

Castro, L.S., Hamilton, T.R.S., Mendes, C.M., Nichi, M., Barnabe, V.H., Visintin, J.A., Assumpção, M.E.O.A., 2016. Sperm cryodamage occurs after rapid freezing phase: flow cytometry approach and antioxidant enzymes activity at different stages of cryopreservation. J. Anim. Sci. Biotechnol. 7, 17.

CBRA, Manual para exame andrológico e avaliação de sêmen animal, second ed., 2013, Colégio Brasileiro de Reprodução Animal; Belo Horizonte, 49 p.

Celeghini, E.C.C., Nascimento, J., Raphael, C.F., Andrade, A.F.C., Arruda, R.P., 2010. Simultaneous assessment of plasmatic, acrosomal, and mitochondrial embranes in ram sperm by fluorescent probes. Arquivos Brasileiros de Medicina Veterinária e Zootecnia 62, 536-543.

Chatterjee, S., Gagnon, C., 2001. Production of reactive oxyge species by spermatozoa undergoing cooling, freezing, and thawing. Mol. Repro. Dev. 59, 451-458.

Darr, R.C., Moraes, R.L., Scanlan, N.T., Baumber-Skaife, J., Loomis, R.P., Coropassi, A.G., Meysers, A.S., 2017. Sperm mitochondrial function is affected by stallion age and predicts post-thaw motility. J. Equine. Vet. Sci. 50, 52-61.

De Iuliis, G.N., Thomson, L.K., Mitchell, L.A., Finnie, J.M., Koppers, A.J., Hedges, A., Nixon, B., Aitken, R.J., 2009. DNA damage in human sperm is highly correlated with the efficiency of chromatin remodeling and the formation of 8-hydroxy-2'-deoxyguanosine, a marker of oxidative stress. Biol. Reprod. 81, 517-524.

Drummen, G.P.C., van Liebergen, L.C.M., Op den Kamp, J.A.F., Post, J.A., 2002. C11-BODIPY(581/591), an oxidation-sensitive fluorescent lipid peroxidation probe: (micro)spectroscopic characterization and validation of methodology. Free Radic. Biol. Med. 33, 473-490.

Fang, L., Bai, C., Chen, Y., Dai, J., Xiang, Y., Ji, X., Huang, C., Dong, Q., 2014. Inhibition of ROS production through mitochondria-targeted antioxidant and mitochondrial uncoupling increases post-thaw sperm viability in yellow catfish. Cryobiology 69, 386-393.

Gravance, C.G., Garner, D.L., Miller, M.G., Berger, T., 2001. Fluorescent probes and flow cytometry to assess rat sperm integrity and mitochondrial function. Reprod. Toxicol. 15, 5-10.

Gürler, H., Calisici, O., Calisici, D., Bollwein, H., 2015. Effects of feeding omega-3-fatty acids on fatty acid composition and quality of bovine sperm and on antioxidative capacity of bovine seminal plasma. Anim. Reprod. Sci. 160, 97-104.

Gürler, H., Malama, E., Heppelmann, M., Calisici, O., Leiding, C., Kastelic, J.P., Bollwein, H., 2016. Effects of cryopreservation on sperm viability, synthesis of reactive oxygen species, and DNA damage of bovine sperm. Theriogenology 86, 562-571.

Hallap, T., Håård, M., Jaakma, Ü., Larsson, B., Rodriguez-Martinez, H., 2004. Variations in quality of frozen-thawed semen from Swedish Red and White AI sires at 1 and 4 years of age. Int. J. Androl. 27, 166-171.

Hallap, T., Jaakma, Ü., Rodriguez-Martinez, H., 2006. Changes in semen quality in Estonian Holstein AI bulls at 3, 5 and 7 years of age. Reprod. Domest. Anim. 41 , 214-218.

Kelso, K.A., Redpath, A., Noble, R.C., Speake, B.K., 1997. Lipid and antioxidant changes in sperm and seminal plasma throughout the reproductive period of bulls. J. Reprod. Fertil. 109, 1-6.

Khoshvaght, A., Towhidi, A., Zare-shahneh, A., Noruozi, M., Zhandi, M., Dadashpour Davachi, N., Karimi, R., 2016. Dietary n-3 PUFAs improve fresh and post-thaw semen quality in Holstein bulls via alteration of sperm fatty acid composition. Theriogenology 85, 807-812.

Kumi-diaka, J., Nagaratnan, V., Rwuan, J.S., 1981. Seasonal and age-related changes in semen quality and testicular morfology of bulls in a tropical environment. Vet. Rec. 108, 13-15.

Lundbeek, J.A., Andersen, O.S., 1994. Lysophospholipids modulate channel function by altering the mechanical properties of lipid bilayers. J. Gen. Physiol. 104, 645-673.

Macías García, B., González Fernández, L., Ortega Ferrusola, C., Salazar-Sandoval, C., Morillo Rodríguez, A., Rodríguez Martinez, H., Tapia, J., Morcuende, D., Peña, F., 2011. Membrane lipids of the stallion spermatozoon in relation to sperm quality and susceptibility to lipid peroxidation. Reprod. Domest. Anim. 46, 141-148.

Mostek, A., Dietrich, M.A., Słowińska, M., Ciereszko, A., 2017. Cryopreservation of bull semen is associated with carbonylation of sperm proteins. Theriogenology 92 , 95-102.

Nichi, M., Bols, P.E.J., Züge, R.M., Barnabe, V.H., Goovaerts, I.G.F., Barnabe, R.C., Cortada, C.N.M., 2006. Seasonal variation in semen quality in bos indicus and bos taurus bulls raised under tropical conditions. Theriogenology 66, 822-828.

Nogueira, G.P., 2004. Puberty in South American Bos indicus (Zebu) cattle. Anim. Reprod. Sci. 82, 361-372.

Ortega Ferrusola, C., González Fernández, L., Morrell, J.M., Salazar Sandoval, C., Macías García, B., Rodríguez-Martinez, H., Tapia, J.A., Peña, F.J., 2009. Lipid peroxidation, assessed with BODIPY-C 11, increases after cryopreservation of stallion sperm, is stallion-dependent and is related to apoptotic-like changes. Reproduction 138, 55-63.

Ozkosem, B., Feinstein, S.I., Fisher, A.B., O'Flaherty, C., 2015. Advancing age increases sperm chromatin damage and impairs fertility in peroxiredoxin 6 null mice. 
Redox Biol. 5, 15-23.

Paul, C., Nagano, M., Robaire, B., 2011. Aging results in differential regulation of dna repair pathways in pachytene spermatocytes in the Brown Norway rat. Biol. Reprod. 85, 1269-1278.

Peña, F.J., Rodríguez Martínez, H., Tapia, J.A., Ortega Ferrusola, C., González Fernández, L., Mać́as García, B., 2009. Mitochondria in mammalian sperm physiology and pathology: a review. Reprod. Domest. Anim. 44, 345-349.

Selvaratnam, J., Paul, C., Robaire, B., 2015. Male rat germ cells display age-dependent and cell-specific susceptibility in response to oxidative stress challenges. Biol. Reprod. 93, 11-17.

Tapia, J.A., Macias-Garcia, B., Miro-Moran, A., Ortega-Ferrusola, C., Salido, G.M., Peña, F.J., Aparicio, I.M., 2012. The membrane of the mammalian sperm: much more than an inert envelope. Reprod. Domest. Anim. 47, 65-75.

Van Tran, L., Malla, B.A., Kumar, S., Tyagi, A.K., 2017. Polyunsaturated fatty acids in male ruminant reproduction - a review. J. Anim. Sci. 30, 622-637.

Weir, C.P., Robaire, B., 2006. Sperm have decreased antioxidant enzymatic capacity and increased reactive oxygen species production during aging in the brown norway rat. J. Androl. 28, 229-240.

Zubkova, E.V., Robaire, B., 2006. Effects of ageing on sperml chromatin and its sensitivity to in vivo and in vitro oxidative challenge in the Brown Norway rat. Hum. Reprod. 21, 2901-2910.

Zubkova, E.V., Wade, M., Robaire, B., 2005. Changes in sperml chromatin packaging and susceptibility to oxidative challenge during aging. Fertil. Steril. 84, $1191-1198$. 